\title{
GROUND-BASED RAYLEIGH-MIE DOPPLER LIDAR FOR WIND MEASUREMENTS IN THE MIDDLE ATMOSPHERE
}

\author{
S. M. Khaykin ${ }^{1 *}$, A. Hauchecorne ${ }^{1}$, J. Porteneuve ${ }^{1}$, J.-F. Mariscal ${ }^{1}$, E. D'Almeida ${ }^{1}$, \\ J.-P. Cammas' ${ }^{2}$, G. Payen ${ }^{2}$, S. Evan ${ }^{2}$, and P. Keckhut ${ }^{1}$ \\ ${ }^{1}$ LATMOS-IPSL, Université Versailles St.-Quenitn, CNRS/INSU, Guyancourt, France, \\ *Email:sergey.khaykin@latmos.ipsl.fr \\ ${ }^{2}$ OSUR, UMS3365, Université de la Réunion, Saint-Denis, La Réunion, France
}

\begin{abstract}
A unique Rayleigh-Mie Doppler wind lidar, measuring Doppler shift between the emitted and backscattered light using directdetection technique is deployed at Observatory of Haute Provence Southern France) and at Reunion island (tropical Indian Ocean). The instrument was shown capable of wind measurements between 5 and $50 \mathrm{~km}$ with accuracy better than $1 \mathrm{~m} / \mathrm{s}$ up to $30 \mathrm{~km}$. The system consists of a monomode $\mathrm{Nd}$ :Yag laser operating at $532 \mathrm{~nm}$, three telescopes and a double-edge Fabry-Perot interferometer. The laser light is sent alternatively in the vertical as well as zonal and meridional directions at $40^{\circ}$ from the zenith using a rotating mirror. The two components of the horizontal wind are obtained from the measurement of the Doppler shift of the return signal spectrally filtered by the FabryPerot etalon. After demonstration of the method in 1989 the measurements were used for studying stratospheric dynamics as well as for constructing wind climatology up to $50 \mathrm{~km}$ altitude. A new system, featuring a more compact design was installed at Maïdo observatory at Reunion Island $\left(21^{\circ} \mathrm{S}\right)$. The design of the instrument, results of observations and comparison against GPS radiosondes are presented. Application of Doppler lidar for validation of the future ADM-Aeolus satellite mission is discussed as well.
\end{abstract}

\section{INTRODUCTION}

Wind measurements above $25 \mathrm{~km}$ are rare. The only information available on a regular basis is zonal mean winds inferred from satellite-borne pressure measurements assuming geostrophic balance. However this does not allow understanding the propagation of gravity waves, whose filtering, dissipation and/or breaking strongly depend on wind speed and direction. Observations of high vertical resolution $(\sim 1 \mathrm{~km})$ are required for detecting wind shears around the stratopause, which play a crucial role in reflecting or filtering of the waves. Following this requirement, a direct- detection Doppler lidar for wind observations in the middle atmosphere has been developed in France in 1989 [1,2]. After deployment of the Doppler lidar at Observatory of Haute Provence (OHP) in Southern France $\left(44^{\circ} \mathrm{N}, 6{ }^{\circ} \mathrm{E}, 600 \mathrm{~m}\right.$ a.s.l.) in 1993 the technique was shown capable of wind measurements between 5 and $50 \mathrm{~km}$ independent of the presence of aerosols [3,4]. The wind lidar was operated on a regular based during 19941999 and occasionally since then. The observations were used to construct wind climatology in the middle atmosphere [3] and to study gravity wave spectra and small-scale wind fluctuations [5].

In 2012 the Rayleigh-Mie Doppler lidar was deployed at a newly established tropical observatory located on mount Maïdo $\left(21^{\circ} \mathrm{S}, 55\right.$ ${ }^{\circ} \mathrm{E}, 2200 \mathrm{~m}$ a.s.1.) at Reunion island [6]. The wind measurements above Reunion Island represent a substantial value for studying the dynamics of the tropical middle atmosphere - a region where observations are particularly sparse. They are also of big relevance for validation of the upcoming European Space Agency (ESA) ADM-Aeolus satellite mission for global observations of wind. ADM-Aeolus mission will carry a Rayleigh-Mie Doppler lidar, based on the same principle as the French Doppler lidars.

\section{METHODOLOGY}

The horizontal wind components are obtained by measuring Doppler shift between emitted and backscattered light by means of a double-edge Fabry-Perot interferometer (directdetection technique). The Doppler shift is due to projection of molecules or particles velocities onto the line of sight of the laser inclined off zenith. The laser beam is sent alternatively to zonal and meridional direction for obtaining both wind components, whereas the vertical pointing is used for measuring the zero Doppler shift reference (in assumption that the vertical wind is 
negligible). A wind velocity of $1 \mathrm{~m} / \mathrm{s}$ corresponds to the Doppler shift of about $2 \mathrm{fm}$ with the off-zenith angle of $40^{\circ}$.

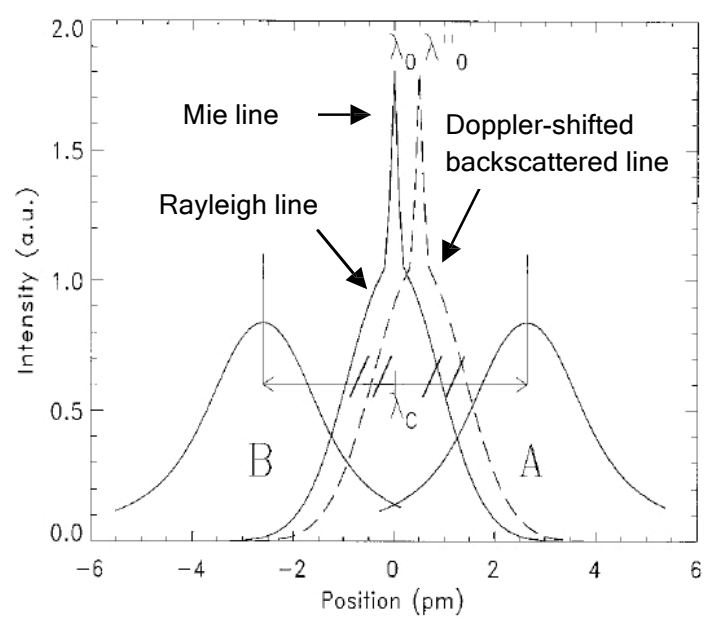

Fig. 1. Shape of the backscattered line embedded between FPI bandpasses. The A and B labels refer to the different areas of FPI [3].

After elastic scattering from air molecules and possibly other particles, the spectral shape of the backscattered laser line shows two distinct components (Fig. 1). The wide part is the Rayleigh component that is broadened because of the random motion of the air molecules. The spectral width can take values between 2 and 2.4 $\mathrm{pm}$ for atmospheric temperature from 200 to 280 $\mathrm{K}$ [3]. The fine Mie component is assumed to have the same spectral width as the laser source and to follow the same Doppler shift as the Rayleigh component. The Doppler-shift determination is provided by a double-edge FPI with two half-disks areas whose air gap is slightly different, resulting in two bandpasses, named A and B. Each area intersects a half-disk of the incoming light. Both bandpasses have a FWHM of $2.03 \mathrm{pm}$ and are spaced $5.24 \mathrm{pm}$ apart. The FPI is set in a sealed chamber ended by a pressure-changing piston driven by a stepper motor. The FPI bandpasses are spectrally tuned symmetrically on both sides of the Rayleigh-Mie backscattered line (see Fig. 1) by air pressure adjustment, i.e., through the adaptation of the air-gap refractive index. For a given line of sight, at an angle $\theta$ from the zenith, we calculate the response $R(z, \theta)$ at each altitude $\mathrm{z}$, defined as

$$
R(z, \theta)=\frac{C N_{A}(z, \theta)-N_{B}(z, \theta)}{C N_{A}(z, \theta)+N_{B}(z, \theta)}
$$

where $N_{A}(\mathrm{z}, \theta)$ and $N_{B}(\mathrm{z}, \theta)$ are the number of photons transmitted through the bandpasses $\mathrm{A}$ and $\mathrm{B}$ respectively; and $C$ is a corrective factor accounting for the possible imbalance between channels $\mathrm{A}$ and $\mathrm{B}$. The response $R(\mathrm{z}, \theta)$ is representative of the backscattered line position with respect to the FPI bandpasses.

\section{DESCRIPTION OF THE INSTRUMENT}

The Doppler lidar uses a Q-switched, injection-seeded, frequency-doubled Nd:YAG laser operating in monomode as a light source. The pulse repetition rate of the laser is $30 \mathrm{~Hz}$, and the energy per pulse is $\sim 330 \mathrm{~mJ}$ at $532 \mathrm{~nm}$ ( $24 \mathrm{~W}$ mean energy). The emitted spectral shape is assumed to be near Gaussian, with a full width at half-maximum (FWHM) of $\sim 0.14 \mathrm{pm}$.

The OHP system includes three fixed subassemblies: one is pointed toward the zenith while the two others are tilted at $40^{\circ}$ off zenith to the North and East directions (Fig. 2). The different subassemblies, i.e. different line of sights are used successfully during the acquisition. The unique laser beam is steered by a rotating mirror with three predefined positions. Each mirror position sends the beam to the chosen subassembly, composed of a central afocal transmitter and four receiving parabolic mirrors providing a total collective area of 0.78 $\mathrm{m}^{2}$.

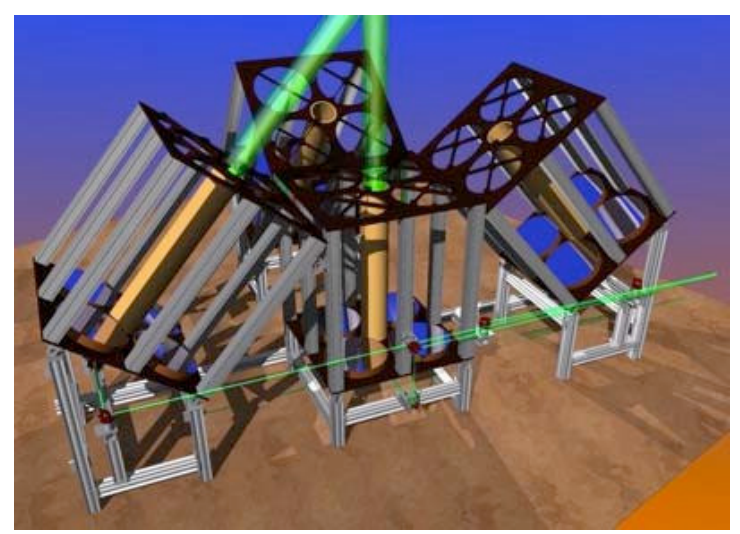

Fig. 2. Schematic view of the lidar optical setup at OHP. Four telescope assemblies for Northward, Eastward, Westward and vertical pointing are shown. The Westward pointing assembly is no longer used.

The photons are collected by means of four multimode optical fibers located at each focal point. A 1-nm bandpass is used as a spectral pre-filter before FPI to reduce the sky background light. The photons $N_{A}$ and $N_{B}$ transmitted through the FPI's bandpasses A and B are detected with R9880U-20 Hamamatsu photomultipliers (PMT's) in photon-counting mode. To extend the altitude range of measurements, there are two pairs of PMT's 
collecting 90\% (high-altitude channels) and 10\% (low-altitude channels) of the signals. The acquisition is done with a Licel transient recorder providing 16384 time bins of $100 \mathrm{~ns}$ width (i.e. $15 \mathrm{~m}$ radial resolution). Electronic obturation is used to protect the PMTs from the strong signals coming from low altitudes. Measurements are limited to nighttime and absence of optically thick clouds. A narrow-band interference filter with $0.1 \mathrm{~nm}$ bandpass, limiting the vertical range and resolution, can be used to extend the operation time frame to twilight conditions.

The Doppler lidar system at Maïdo observatory makes use of the same laser and acquisition system as those at OHP but features a more compact design of the reception set-up. The telescope is composed of a single rotating mirror, which serves for both the emission and reception. The collective area of the telescope is $0.3 \mathrm{~m}^{2}$. The smaller collective area compared to OHP lidar is compensated by the high elevation of the station and cleaner atmosphere above the Indian Ocean.

\section{RESULTS}

The OHP Doppler lidar has been operated on a regular basis during 1994-1998 and on a campaign basis since then. The wind observations were used to build the climatology of wind velocity components in the $12-50 \mathrm{~km}$ height range [3] and for retrieving the gravity wave vertical wavenumber and apparent spectra as well as for constructing the time series of wave kinetic energy [5]. The error estimates showed the $1-\sigma$ uncertainty varying significantly with altitude and integration time; for $115 \mathrm{~m}$ vertical resolution the uncertainty ranges from $0.8 \mathrm{~m} / \mathrm{s}$ at $13 \mathrm{~km}$ for 1 hour integration time to $6.8 \mathrm{~m} / \mathrm{s}$ at $20 \mathrm{~km}$ for $5 \mathrm{~min}$ integration. For an entire night of integration ( 7 hours) the uncertainty stays below $1 \mathrm{~m} / \mathrm{s}$ up to $30 \mathrm{~km}$ altitude [5]. These estimates are confirmed by intercomparison with GPS-equipped radiosondes [3].

The new Maïdo Doppler lidar was deployed in 2012 and brought to a nominal operation in 2014. It is currently operated on a campaign basis [7]. Fig. 3 shows the results of comparison of wind profiles obtained with Doppler lidar ( $2 \mathrm{~h}$ integration time) against the radiosounding data and European Center for Medium-Range Weather Forecast (ECMWF) operational analysis. The mean of two radiosoundings launched at $15 \mathrm{~h}$ local time from a location $\sim 30 \mathrm{~km}$ away was used for intercomparison with the lidar, whose operation was started around midnight. The results of comparison show good agreement of lidar profiles (low- and high-altitude channels) of both zonal and meridional wind components with those of radiosondes above $7 \mathrm{~km}$ altitude. The ECMWF zonal and meridional wind profiles agree well with the radiosonde throughout the entire altitude range and confirm the vertical structure observed by the lidar between 30 and $43 \mathrm{~km}$, where the error in lidar profile becomes substantial. For better accuracy in the upper stratosphere a longer than 2 hours integration time is required.
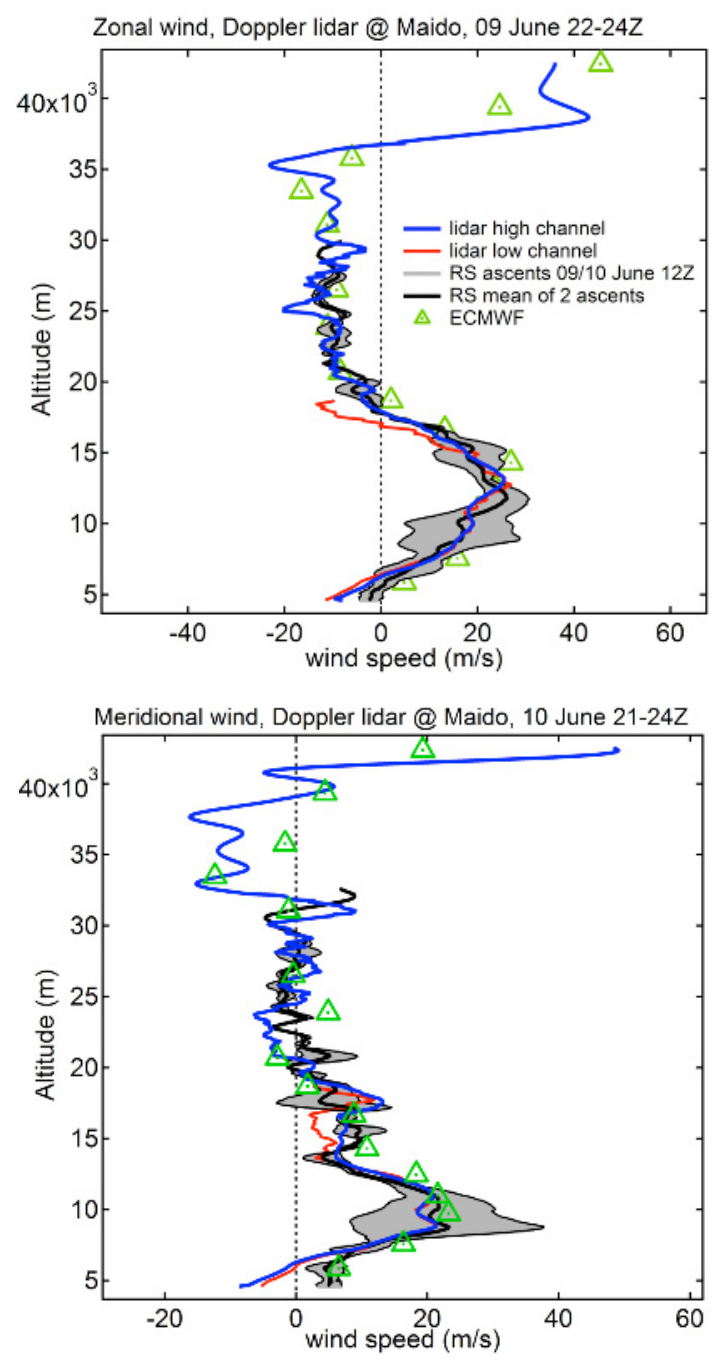

Fig. 3. Comparison of zonal (top) and meridional (bottom) wind velocity profiles obtained using Maïdo Doppler lidar on 09 and 10 June 2014 with the corresponding M10 GPS radiosondes and ECMWF operational analysis. Grey-shaded area indicates the range of values from radiosonde profiles.

\section{VALIDATION OF ADM-AEOLUS USING DOPPLER LIDARS}

The ESA ADM-Aeolus is the first mission 
to provide global observations of wind from the lower troposphere up to about $30 \mathrm{~km}$ altitude. The satellite is expected to be launched and set into sun-synchronous orbit in late 2016. The Atmospheric LAser Doppler INstrument (ALADIN) instrument onboard Aeolus is composed of a laser emitting at $355 \mathrm{~nm}$ and a $1.5-\mathrm{m}$ telescope. The Doppler shift is detected using Fizeau and Fabry-Perot interferometers for Mie and Rayleigh scattering analysis respectively. A similarity of the measurement techniques exploited by ALADIN (Rayleigh channel) and by the French ground-based Doppler lidars makes the latter an attractive mean for Aeolus validation. We present a proposal for ADM-Aeolus CAL/VAL activities based on the operations of two wind lidars operating at mid-latitude and tropical sites.

The validation program includes a preCAL/VAL phase aimed at development of a spatial-temporal collocation criteria for groundbased/satellite measurement match. An advantage of the Doppler lidar with respect to conventional GPS radiosondes is that the lidar provides continuous high-resolution wind measurements that can be used to determine temporal collocation criteria for validation of ADM-Aeolus. The spatial collocation criteria will be defined using a dense radiosonde network in Europe.

\section{SUMMARY}

Two direct-detection Rayleigh-Mie Doppler wind lidars are deployed at mid-latitude (OHP) and tropical (Maïdo) sites. The lidar is shown capable of wind measurements between 5 and $50 \mathrm{~km}$ with accuracy better than $1 \mathrm{~m} / \mathrm{s}$ up to $30 \mathrm{~km}$. Observations are used for studying mesoscale wind fluctuations and gravity waves in the mid-stratosphere as well as for constructing wind climatology up to $50 \mathrm{~km}$ altitude. The results of comparison with GPS radiosondes suggest good performance of the Doppler lidars and confirm the error estimates. A validation program for ADM-Aeolus space mission is described. The validation activities include the development of spatiotemporal collocation criteria based on continuous measurements by ground-based lidar and radiosonde network.

\section{ACKWNOLEDGEMENTS}

The work was supported by the French National Space Agency (CNES), CNRS-INSU and by the EU FP7 ARISE project.

\section{REFERENCES}

[1] Chanin, M. L, A. Garnier, A. Hauchecorne, J. Porteneuve (1989): A Doppler lidar for measuring winds in the middle atmosphere, Geophys. Res. Lett., 16(11), 1273-1276.

[2] Garnier A., M. L. Chanin, 1992: Description of a Doppler Rayleigh lidar for measuring winds in the middle atmosphere, Appl. Phys., B, 55, 35-40.

[3] Souprayen, C., A. Garnier, A. Hertzog, A. Hauchecorne, J. Porteneuve (1999): RayleighMie Doppler wind lidar for atmospheric measurements. I. Instrumental setup, validation, and first climatological results, Appl. Opt., 38, 12.

[4] C. Souprayen, A. Garnier, and A. Hertzog (1998): Rayleigh-Mie Doppler wind lidar for atmospheric measurements. II. Mie scattering effect, theory, and calibration, Appl. Opt., 2422- 2431.

[5] Hertzog, A., C. Souprayen and A. Hertzog (2001): Measurements of gravity wave activity in the lower stratosphere by Doppler lidar, J. Geophys. Res., 106, D8, 78797890.

[6] Baray, J.-L., Courcoux, Y., Keckhut, P., Portafaix, T., Tulet, P., Cammas, J.-P., Hauchecorne, A., Godin Beekmann, S., De Mazière, M., Hermans, C., Desmet, F., Sellegri, K., Colomb, A., Ramonet, M., Sciare, J., Vuillemin, C., Hoareau, C., Dionisi, D., Duflot, V., Vérèmes, H., Porteneuve, J., Gabarrot, F., Gaudo, T., Metzger, J.-M., Payen, G., Leclair de Bellevue, J., Barthe, C., Posny, F., Ricaud, P., Abchiche, A., and Delmas, R.: Maïdo observatory: a new high-altitude station facility at Reunion Island $\left(21^{\circ} \mathrm{S}, 55^{\circ} \mathrm{E}\right)$ for long-term atmospheric remote sensing and in situ measurements, Atmos. Meas. Tech., 6, 28652877, doi:10.5194/amt-6-2865-2013, 2013.

[7] Keckhut, P., Y. Courcoux, J-L. Baray, J. Porteneuve, H. Vérèmes, A. Hauchecorne, D. Dionisi, F. Posny, J-P. Cammas, G. Payen, F. Gabarrot, S. Evan, S. Khaykin, R. Rüfenacht, B.Tschanz, N. Kämpfer, Ph. Ricaud, A. Abchiche, J.Leclair-de-Bellevue, V. Duflot (2015): Introduction to the MALICCA campaign dedicated to the validation of Upper Air meteorological parameters, J. Appl. Rem. Sens., in press. 